\title{
TELEMEDICAL MARITIME ASSISTANCE SERVICE AT THE UNIVERSITY CENTER OF MARITIME AND TROPICAL MEDICINE IN GDYNIA. THE ANALYSIS OF 6 YEARS OF ACTIVITY
}

\author{
Joanna Szafran-Dobrowolska, Marcin Renke, Wojciech Wołyniec \\ Medical University of Gdańsk, Gdańsk, Poland \\ Institute of Maritime and Tropical Medicine, Department of Occupational, Metabolic and Internal Diseases
}

\begin{abstract}
Background: In the 1960s, the International Labour Organization passed a convention under which all countries with national shipping were obliged to create a 24 -h telemedicine center for ships. In accordance with the convention, Telemedical Assistance Service centers were to provide permanent access to medical advice given by qualified doctors and to create an international platform for the exchange of information and experience. In Poland, the Telemedical Maritime Assistance Service (TMAS) was established in 2012, and its duties in a 24-h system are carried out by doctors from the University Center of Maritime and Tropical Medicine (UCMTM) in Gdynia. The aim of this work was to determine the reasons for medical officers reporting for help from the TMAS doctor on duty and to create a database of the most common diagnoses and actions undertaken, and in particular evacuation. Material and Methods: In the presented work, the authors analyzed TMAS telephony and e-mail advice provided by doctors of the UCMTM in Gdynia, in the period from October 2012 to the end of 2018. Results: In the 6-year period, UCMTM doctors provided TMAS advice 225 times, recommending evacuation in over $20 \%$ of these cases. Infectious diseases were the most common cause of contact in the entire period under analysis - 61 cases were recorded, accounting for as many as $27 \%$ of all applications. Injuries were the second most frequent reason for seeking help from TMAS, and 20\% of TMAS applications (44 cases) were related to trauma. Conclusions: The obtained data show that TMAS doctors face various medical problems; therefore, providing proper medical assistance to patients requires a close multidisciplinary cooperation between medical officers, TMAS doctors and emergency services. Med Pr. 2020;71(2):121-5
\end{abstract}

Key words: occupational exposure, telemedicine, emergency responders, naval medicine, ships, maritime rescue system

Corresponding author: Joanna Szafran-Dobrowolska, Medical University of Gdańsk, Institute of Maritime and Tropical Medicine, Department of Occupational, Metabolic and Internal Diseases, Powstania Styczniowego 9b, 81-519 Gdynia, Poland, e-mail: joannaewaszafran@gmail.com

Received: May 16, 2019, accepted: October 8, 2019

\section{INTRODUCTION}

In 1958, the International Labour Organization (ILO) issued Medical Advice at Sea Recommendation No. 106 under which all members of ILO should provide a $24-\mathrm{h}$ telemedicine center for ships. The first recommendations were then followed by ILO Convention 164 [1] which obliged all countries with national shipping to provide $24-\mathrm{h}$ free of charge medical advice available through the radio - the Telemedical Maritime Assistance Service (TMAS).

Currently, TMAS centers operate on various principles in more than 60 countries around the world. In Poland, the TMAS center was established in 2012 under the Act on Maritime Safety of August 18, 2011 [2], and its duties in a 24 -h system are carried out by doc- tors from the University Center of Maritime and Tropical Medicine (UCMTM) in Gdynia [3].

\section{Aims}

The aim of this work was to determine the reasons for medical officers reporting for help from the TMAS doctor on duty and to create a database of the most common diagnoses and actions undertaken, and in particular evacuation.

The authors believe that the knowledge of the most frequently reported ailments will allow for the implementation of adequate prevention methods, a better preparation of medical officers, marine rescuers and doctors giving advice, and the introduction of possible changes in the medical equipment of sea-going vessels. Improving the health and safety of seafarers will then 
translate into lower morbidity and mortality among people working at sea.

\section{MATERIAL AND METHODS}

In the presented work, the authors analyzed TMAS telephony and e-mail advice provided by doctors of the UCMTM in Gdynia, in the period from October 2012 to the end of 2018. The collected data were analyzed with respect to the number of participants in each year, the most common causes of contact, recommended evacuations and specialist consultations. The data were also analyzed in terms of the age structure, sex and nationality of the victims.

For the purpose of this analysis, the collected reports were also divided into 10 groups based on the most frequent diagnoses (starting with 2017, the ICD-10 classification was used). The authors did not have personal data of the injured, and it was uncertain whether all the evacuations recommended had actually been carried out.

\section{RESULTS}

In the period from 1 October 2012 to the end of 2018, UCMTM doctors gave TMAS advice 225 times (Figure 1), recommending evacuation in over $20 \%$ of these cases. Based on the diagnoses, 10 groups of patients were distinguished:
1) infections,

2) injuries,

3) abdominal pain,

4) cardiovascular diseases (CVDs),

5) musculoskeletal disorders (MSDs) not related to trauma,

6) urologic diseases,

7) chronic diseases,

8) poisonings,

9) mental disorders,

10) other.

In the period under analysis, in 12 cases providing advice required consultations with a specialist - a psychiatrist, a surgeon, an ophthalmologist, a laryngologist, an orthopedist or a specialist in tropical medicine.

\section{Infections}

Infectious diseases were the most common cause of contact in the entire period under analysis, with 61 cases being recorded, accounting for as many as $27 \%$ of all applications, and also in individual years (except for 2015 and 2018 where injuries prevailed). Most cases concerned upper respiratory tract infections, which accounted for almost $40 \%$ of all infections and $10 \%$ of all reports (23 patients). Other frequent causes were urinary tract infections ( 8 cases) and fever with undetermined etiology (7 cases). In addition, 4 suspicions of malaria were reported. Particularly noteworthy is the

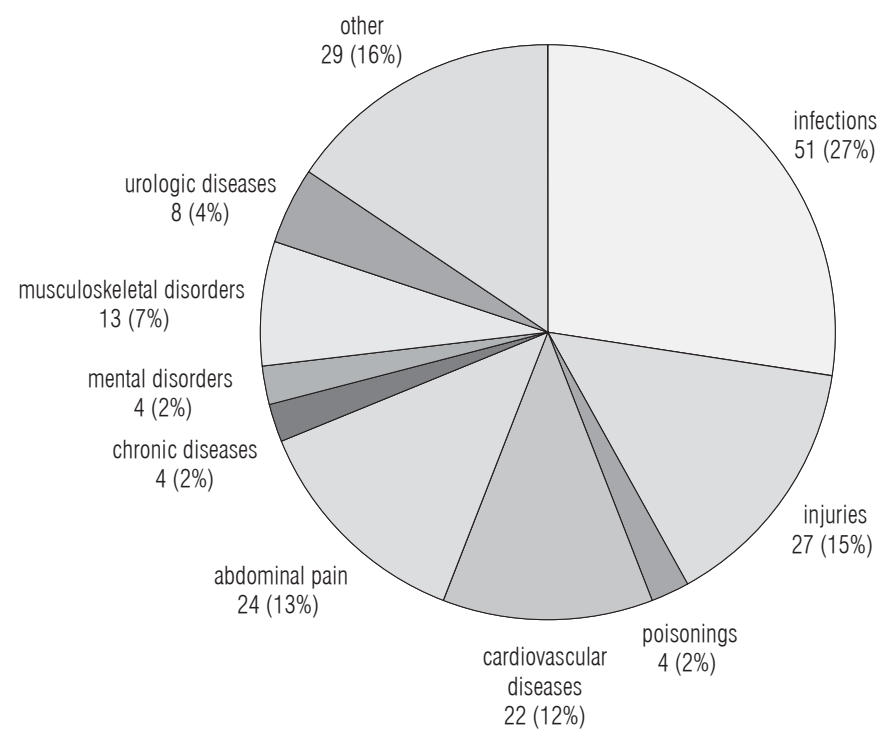

Figure 1. Advice provided by the Polish Maritime Telemedical Assistance Service in 2012-2018 depending on the diagnosis 
fact that all cases of urogenital infections were diagnosed in the 20-39 age group.

\section{Injuries}

The second most frequent reason for seeking help from TMAS doctors were injuries $-17.5 \%$ of all TMAS applications (39 cases) were related to trauma, one-third of which were burns of various parts of the body. Other frequent injuries included limb injuries and falls. There were also isolated cases of injuries of the eye area or foreign bodies in the eye, requiring ophthalmological consultations, and insect or fish bites. The collected data on injuries are, unfortunately, incomplete because in the initial observation period (2013-2014) no types of injuries were entered into the TMAS documentation.

\section{Abdominal pain}

Abdominal pain of various etiologies formed another group of recurring diagnoses, accounting for about $12 \%$ of all reports (27 cases). Abdominal pain with undetermined etiology was also the third most common cause of evacuation (5 evacuations, 10\%).

\section{Cardiovascular diseases}

Particularly noteworthy are diseases of the cardiovascular system, which were the fourth reason, preceded by infections, trauma and abdominal pain, for TMAS applications (27 patients, $12 \%$ ), and which, at the same time, were the cause of $25 \%$ of recommended evacuations. In the presented work, this group of diagnoses was divided into 5 subgroups - arterial hypertension, chest pain, strokes/suspicion, arrhythmias and other cardiovascular symptoms. Of the subgroups mentioned, the most common were chest pains.

\section{Other}

Other frequent reasons for TMAS reports included MSDs (related mainly to degenerative joint diseases), chronic diseases, e.g., diabetes type 2, as well as mental disorders including acute psychosis.

\section{Evacuations}

Over 6 years of the follow-up period, 49 evacuations were recommended, with 13 patients evacuated due to CVDs (>26\%), 12 after trauma (24\%), and 5 due to abdominal pain $(10 \%)$. The average age of the evacuees was 50 years (Figure 2).

\section{Demographic structure}

The average age of persons requiring assistance was about 44 years; the oldest person was 70 years old and the youngest -20 . The standard deviation regarding age of the seafarers to whom advice was given amounted to 13.36101994 . Considering that over $98 \%$ of people working at sea are men [4], it was not surprising that 192 patients were men, and only 33 were women

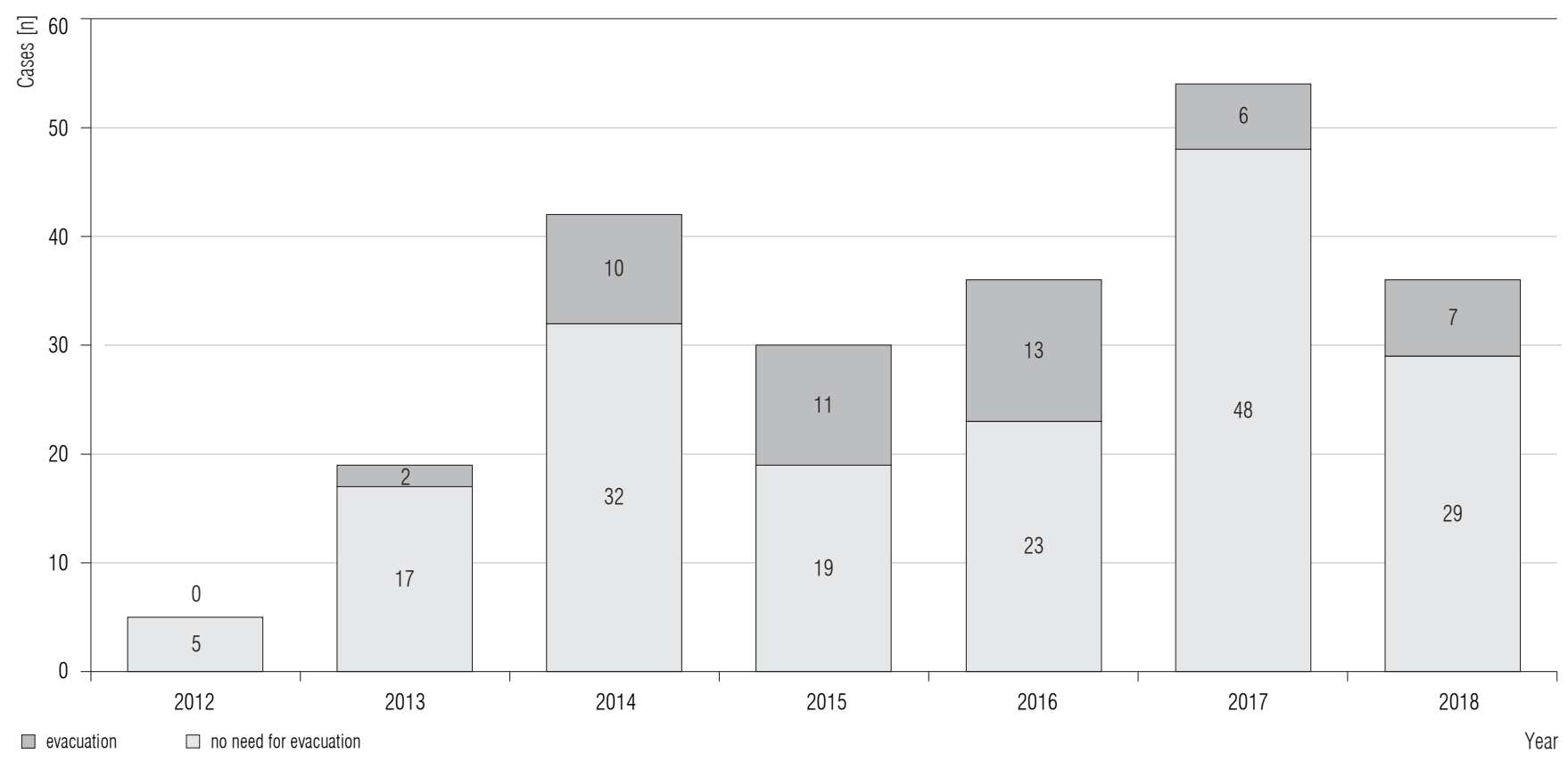

Figure 2. Evacuation recommendations in individual years within the advice provided by the Polish Maritime Telemedical Assistance Service in 2012-2018 
(1 notification concerned labor in progress). Poles constituted more than half of the patients. Advice was given mainly to ship crews (92\%), but in 18 cases it concerned passengers. Passengers were older, their average age being 47 years.

\section{Mass accidents}

In 2015, there were 2 incidents involving more than one injured person. In January 2015, a TMAS call concerned the method of assisting 7 chilled survivors taken from the life raft; in September 2015, there was a collective poisoning of $16 \mathrm{crew}$ members, of whom 2 officers eventually died.

\section{DISCUSSION}

The TMAS center is an important element of the international maritime rescue system. In the period under analysis, infectious diseases were the most common. The results presented in this paper concerning infectious diseases are comparable to the results of Swedish research evaluating TMAS reports dated 1997, 2002, 2007, and 2009, in which infectious diseases, mainly respiratory tract infections, gastrointestinal and skin diseases, accounted for $33 \%$ of all TMAS contacts [5]. What is more, infectious diseases were, according to a study by Kaerlev et al., the first reason for hospital contacts for non-officers among Danish seafarers in 1994-1998 [6].

In this regard, the authors consider that particular attention should be paid to the prevention of infectious diseases, mainly the upper respiratory tract and the spread of infections among the crew, and to education in the field of sexually transmitted diseases especially among crew members under 40 years of age. Education in this field, especially among young crew members, is particularly important as, according to the previously mentioned article by Kaerlev et al., the number of seafarers contacting the hospital due to HIV infection did not decline between 1994-1999 and 2005 [6]. In addition, a Turkish study proved that undergraduate maritime students showed a very low risk perception in the field of communicable diseases [7]. Equally important is the regular training of the crew in the field of safety, both during work and rest on the ship, because different types of injuries are the second most common reason for reporting. The presented results, concerning a relatively small group of cases, find confirmation in a large study published in 2019 by Çakır and Arslan concerning 5080 contacts in the last 4 years of the functioning of the Turkish Telemedical Assistance
Service. In the Turkish analysis, injuries and poisonings were the most common causes of TMAS contacts both among seafarers and passengers [8].

What is more, eye injuries mostly required the doctor on duty to seek advice from a specialist in the field of ophthalmology, which may suggest their particular seriousness. Medical officers on the ship should be thoroughly trained to deal with injuries, especially burns, fractures and eye injuries. The characteristics of the most common types of injuries are similar to Napoleone's conclusions drawn from the evaluation of case histories from Centro Internazionale Radio Medico in Rome in 2010-2015 [9].

Cardiovascular diseases are another group of diseases to which attention should be paid as they were the third most common cause of reports, and the first most common reason for evacuation recommendations, which - from the point of view of emergency services, ship owners and patients - is not a desirable situation. The main conclusions regarding the causes of evacuation recommended by the Polish TMAS center coincide with the previously mentioned Swedish study conducted by Westlund et al. [5], in which it was observed that, except for non-specific diagnoses, diagnoses of injuries and CVDs were the most frequently occurring causes of evacuation among Swedish crews and ship passengers.

In Poland, the law regarding the criteria of admission to employment was liberalized in 2015. Under the new rules, sailors with a CVD history may be permitted to work under certain conditions, which was not possible before.

Interestingly, the change in the law did not significantly affect the total number of CVD-related reports in the subsequent years under analysis (2016-2018). Paradoxically, however, the subgroup of patients reporting chest pains decreased from about 3-4 to about 1 case per year, which may suggest a better level of care and compliance in these patients, due to the lack of necessity to hide their medical history. However, CVDs are still the leading cause of death in both the general population and among seafarers [10]. Therefore, it is important to highlight the need to promote a lifestyle change for seafarers, among whom the CVD risk factors are common [11].

\section{CONCLUSIONS}

The obtained data show that TMAS doctors face various medical problems; therefore, providing proper medical 
assistance to patients requires a close multidisciplinary cooperation between medical officers, TMAS doctors and emergency services. The introduction of more advanced methods of contact between TMAS doctors and medical officers, such as a videophone, would be helpful. A tele-ECG device or a simple diagnostic test designed to confirm the presence of specific pathogens (e.g., the rapid influenza diagnostic test) may improve the diagnostic process and, therefore, enable a quicker diagnosis of severe conditions along with verifying the need for the patient to be isolated.

\section{REFERENCES}

1. International Labour Organization [Internet]. The Organization; 1987 [cited 2019 May 7]. C164 - Health Protection and Medical Care (Seafarers) Convention, 1987 (No. 164). Available from: https://www.ilo.org/dyn/normlex/en/f?p=NORMLEXPUB:12100:0::NO::P12100_ILO_ CODE:C164.

2. [Act of 18 August 2011 on maritime safety. J Laws 2011 No. 288, item 1366]. Polish.

3. Kurlapski M, Wójcik-Stasiak M, Klincewicz P, Januszczyk J, Wołyniec W, Renke M, et al. TMAS - Maritime Telemedical Assistance Service at the University Centre of Maritime and Tropical Medicine in Gdynia. The first year activity report. Int Marit Health. 2014;65(3):174, https://doi.org/10.5603/ IMH.2014.0033.

4. European Maritime Safety Agency [Internet]. 2017 [cited 2019 May 7]. Seafarers' Statistics in the EU Statistical review
(2015 data STCW-IS). Available from: http://emsa.europa. eu/infographics/item/3322-seafarer-statistics-in-the-eu2016.html.

5. Westlund K, Attvall S, Nilsson R, Jensen OC. Telemedical Maritime Assistance Service (TMAS) to Swedish merchant and passengers ships 1997-2012. Int Marit Health. 2016;67(1):24-30, https://doi.org/10.5603/IMH.2016.0006.

6. Kaerlev L, Jensen A, Hannerz H. Surveillance of hospital contacts among Danish seafarers and fishermen with focus on skin and infectious diseases-a population-based cohort study. Int J Environ Res Public Health. 2014;11(11):1193149, https://doi.org/10.3390/ijerph111111931.

7. Turkistanli TT, Sevgili C. Awareness of health risks and communicable diseases among undergraduate maritime students. Int Marit Health. 2018;69(2):142-8, https://doi. org/10.5603/IMH.2018.0021.

8. Çakır E, Arslan Ö. Turkish Telemedical Assistance Service: last four years of activity. Int Marit Health. 2018;69(3): 184-91, https://doi.org/10.5603/IMH.2018.0030.

9. Napoleone P. Accidents on board merchant ships. Suggestions based on Centro Internazionale Radio Medico (CIRM) experience. Int Marit Health. 2016;67(1):21-3, https://doi.org/10.5603/IMH.2016.0005.

10. Oldenburg M. Risk of cardiovascular diseases in seafarers. Int Marit Health. 2014;65(2):53-7, https://doi.org/10.5603/ IMH.2014.0012.

11. Filikowski J, Rzepiak M, Renke W, Winnicka A, Smolińska D. Selected risk factors of ischemic heart disease in Polish seafarers. Preliminary report. Int Marit Health. 2003;54(1-4):40.

This work is available in Open Access model and licensed under a Creative Commons Attribution-NonCommercial 3.0 Poland License - http://creativecommons.org/licenses/by-nc/3.0/pl/deed.en. 